\title{
COMPARISON OF ARTIFICIAL NEURAL NETWORKS AND FUZZY LOGIC APPROACHES FOR CRACK DETECTION IN A BEAM LIKE STRUCTURE
}

\author{
B Prakruthi Gowd ${ }^{1}$, K Jayasree ${ }^{2}$ and Manjunath N. Hegde ${ }^{3}$ \\ ${ }^{1}$ Assistant Professor, Department of Civil Engineering, \\ Vidya Jyothi Institute of Technology, Hyderabad, India. \\ ${ }^{2}$ Assistant Professor, Department of Civil Engineering, \\ Vasavi College of Engineering, Hyderabad, India. \\ ${ }^{3}$ Professor and Dean (Academics), Department of Civil Engineering, \\ Dr. Ambedkar Institute of Technology, Bengaluru, India.
}

\begin{abstract}
This paper proposes two algorithms of crack detection one using fuzzy logic (FL) and the other artificial neural networks (ANN). Since modal parameters are very sensitive to damages, the first three relative natural frequencies are used as three inputs and the corresponding relative crack location, relative crack depth are used as the two outputs in the algorithms. The three natural frequencies for an undamaged beam and different cases of damaged beam (Single crack at various locations with varying depths) were obtained by modelling and simulating the beams using a finite element based (FEM) software. Results concluded that both the approaches can be successfully employed in crack detection in a beam like structure but FL approach performed better in determining relative crack depth whereas ANN approach performed better in determining relative crack location. All the comparisons made in the study are based on the $R^{2}$ values.
\end{abstract}

\section{KEYWORDS}

Damage detection, Modal Properties, Artificial Neural Networks, Fuzzy Logic, $R^{2}$ values.

\section{INTRODUCTION}

Structures such as buildings, bridges, or any other, are prone to sudden damage, deterioration and aging during their service life. The existence of damage in these structures presents a serious threat to the longevity of these structures. Furthermore, the presence of damage can affect the performance of these structures and influence structural integrity of other parts which are associated with them. Detection of these damages at an early stage can allow engineers have enough time to make careful decisions on whether to repair the part of the structure which is damaged while the structure is still in operation or to temporarily keep the structure out of service or to entirely discard the structure. This can possibly avoid many undesirable failures of damaged structures, which if left unnoticed would lead to lack of public safety, reduction in the life span of the structure and huge economic losses. Therefore, a health monitoring system or an effective detection technique is required that will be able to detect and identify the damage in real time and 
at the earliest stage possible, so as to maintain the structural stability, integrity and to maximize the life span of the structure as much as possible.

Many techniques have been employed in the past for damage detection. Some of these are Visual inspection, Non-destructive testing and Use of sensors to detect local damage. These methods take a lot of time and do need the testing of the entire structure in minute detail to tell if the structure is damaged. Furthermore, if a damage is deep inside the structure it may not be detectable by these localized methods. Based on the changes in the modal parameters researchers have developed many signal processing and artificial intelligence based techniques for damage identification for any kind of damage detection. These methods have been designed with an aim for faster and accurate estimation of the presence of damage in the structures even from a remote place.

Motivated by the above reasons, this work aims at exploring the use of artificial intelligence techniques such as artificial neural networks and fuzzy logic approaches in determining the damages in engineering structures at an early stage by capturing the vibration parameters.

\section{THEORETICAL BACKGROUND}

The following section gives a brief theoretical insight of the two approaches which are used for developing the damage detection algorithms individually and also their differences.

\subsection{Fuzzy logic}

Fuzzy Logic belongs to the family of many-valued logic. It focuses on fixed and approximate reasoning opposed to fixed and exact reasoning. A variable in fuzzy logic can take a truth value range between 0 and 1, as opposed to taking true or false in traditional binary sets. Since the truth value is a range, it can handle partial truth. Beginning of fuzzy logic was marked in 1965, with the introduction of fuzzy set theory by Lotfi Zadeh [1]. Fuzzy logic provides a method to make definite decisions based on imprecise and ambiguous input data.

\subsection{Artificial Neural Networks}

ANN is a computational model that is developed based on the biological neural networks. An ANN is made up of artificial neurons that are connecting with each other. Typically, an ANN adapts its structure based on the information coming to it. A set of systematic steps called learning rules needs to be followed when developing an ANN. Further, the learning process requires learning data to discover the best operating point of the ANN. ANN's can be used to learn an approximation function for some observed data. But when applying ANN, there are several factors one has to consider [2]. The model has to be carefully selected depending on the data. Using unnecessarily complex models would make the learning process harder. Choosing the correct learning algorithm is also important, since some learning algorithms perform better with certain types of data.

\subsection{Difference between Artificial Neural Networks and Fuzzy Logic}

Fuzzy logic allows making definite decisions based on imprecise or ambiguous data, whereas ANN tries to incorporate human thinking process to solve problems without mathematically modelling them. Even though both of these methods can be used to solve nonlinear problems, and problems that are not properly specified, they are not related. In contrast to Fuzzy logic, ANN tries to apply the thinking process in the human brain to solve problems. Further, ANN includes a 
International Journal of Artificial Intelligence and Applications (IJAIA), Vol.9, No.1, January 2018

learning process that involves learning algorithms and requires training data whereas fuzzy logic includes development of membership functions and rules to relate them [3].

The brief overview of the work done so far related to the above work is as follows: The relationship between the physical damage to a structure and changes in the dynamic characteristic has been studied by Richardson [4]. In his survey he has focused on modal analysis, modal testing method, and relation between the extent of damage and changes in the modes of vibration. During a review process of structural health monitoring, Rytter [5] has classified the damage detection technique as four levels. The level 1 determines the presence of damage in structures. The level 2 determines the geometric location of the damage. The level 3 quantifies the extent of damage and level 4 predicates the life of the structure. The local flexibility that affects the vibration signatures has been suggested by Dimarogonas [6] in his review paper. The crack opening and closing happen in time that depends upon the vibration and rotation amplitude. He has suggested that the local stiffness matrix at the cracked section of a shaft leads to a coupled system and for uncracked shaft, the system is decoupled. A fuzzy rule-based system [7] is developed for the blade of a BO105 helicopter rotor modeled as a cantilever beam and demonstrated that the fuzzy system performs accurately even in the existence of noisy data. De Miguel and Blázquez [8] developed a decision making module based on fuzzy logic for model based fault diagnosis applications. A fault detection and isolation system based on the input and output parameters was successfully applied in laboratory equipment to reduce the uncertainties of the output parameter. Bakhary et al. [9] have explained a statistical approach to take into account the effect of uncertainties in developing an ANN model. Chandrasekhar and Ganguli [10] showed that geometric and measurement uncertainty causes considerable problem in the damage assessment. They used Monte Carlo simulation to study the changes in the damage indicator due to uncertainty in the geometric properties of the beam. The results obtained from the simulation were used for developing and testing the fuzzy logic system. They addressed the uncertainty associated with the fuzzy logic system for structural damage detection. Das and Parhi [11] have extended the application of neural network technique for studying the fault diagnosis of a cracked cantilever beam.

\section{FINITE ELEMENT MODELLING AND SIMULATION}

\subsection{Methodology}

The methodology followed here is to use a FEM package software namely ANSYS 12.1 to model beam like structures (flats) with fixed end condition which include both damaged and undamaged once. Furthermore, modal analysis is carried out in order to obtain the natural frequencies. The variation of these natural frequencies have been analysed for different cases of the damaged structures with respect to the undamaged one so that they can be used further in developing the two damage detection algorithms.

\subsection{Model properties and Cases studied}

The material and geometric properties of the model are as shown in Table 1 and Figure 1. An element type of Solid-Brick-2 noded 188 and element mesh division of 0.0025 is used during FEM modelling. A total of 84 different damaged cases were studied and are described below in Table 2. 
International Journal of Artificial Intelligence and Applications (IJAIA), Vol.9, No.1, January 2018

Table 1. Material and Geometric properties.

\begin{tabular}{|l|l|l|l|l|l|l|}
\hline $\begin{array}{l}\text { Young's Modulus } \\
(\mathbf{E}), \mathbf{G P a}\end{array}$ & $\begin{array}{l}\text { Poisson's } \\
\text { Ratio }(\boldsymbol{\mu})\end{array}$ & $\begin{array}{l}\text { Density } \mathbf{( d )}, \\
\mathbf{K g} / \mathbf{m}^{\mathbf{3}}\end{array}$ & $\begin{array}{l}\text { Length } \\
(\mathbf{l}), \mathbf{m m}\end{array}$ & $\begin{array}{l}\text { Width } \\
(\mathbf{b}), \mathbf{m m}\end{array}$ & $\begin{array}{l}\text { Depth } \\
(\mathbf{d}), \mathbf{m m}\end{array}$ & $\begin{array}{l}\text { End } \\
\text { Conditions }\end{array}$ \\
\hline 210 & 0.3 & 7850 & 3000 & 50 & 200 & Fixed \\
\hline
\end{tabular}

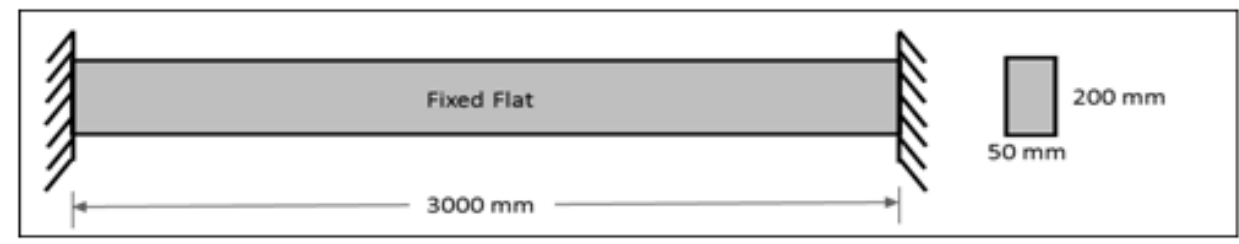

Figure 1. Undamaged Beam like structure (Flat)

Table 2. Cases Studied.

\begin{tabular}{|l|l|}
\hline Crack Depths (cd) & $\begin{array}{l}\text { Varies from 10mm to 120mm (increasing at an interval of 10 mm) (12 } \\
\text { varying depths) }\end{array}$ \\
\hline Crack Locations (cl) & Varies from L/2 to L/16 from the fixed end (7 different locations) \\
\hline
\end{tabular}

Note: Thickness of the crack is taken as $1 \mathrm{~mm}$ for all the cases.

\subsection{Results of Modal Analysis}

The natural frequencies and mode shape deflections of the undamaged flat model obtained from ANSYS are as shown in Table 3 and Figure 2. In order to study the variation of the natural frequencies for different damaged cases the relative natural frequencies are calculated with the help of the results obtained from ANSYS.

$$
\text { Relative Natural Frequency }=\frac{\text { Natural Frequency of the Damaged Flat }}{\text { Natural Frequency of the Undamaged Flat... }}
$$

Table 3. Natural Frequency of Undamaged Flat.

\begin{tabular}{|l|l|l|}
\hline $\begin{array}{l}\text { First Natural } \\
\text { Frequency, Hz }\end{array}$ & $\begin{array}{l}\text { Second Natural } \\
\text { Frequency, Hz }\end{array}$ & $\begin{array}{l}\text { Third Natural } \\
\text { Frequency, } \mathbf{H z}\end{array}$ \\
\hline 112.49 & 299.39 & 562.35 \\
\hline
\end{tabular}
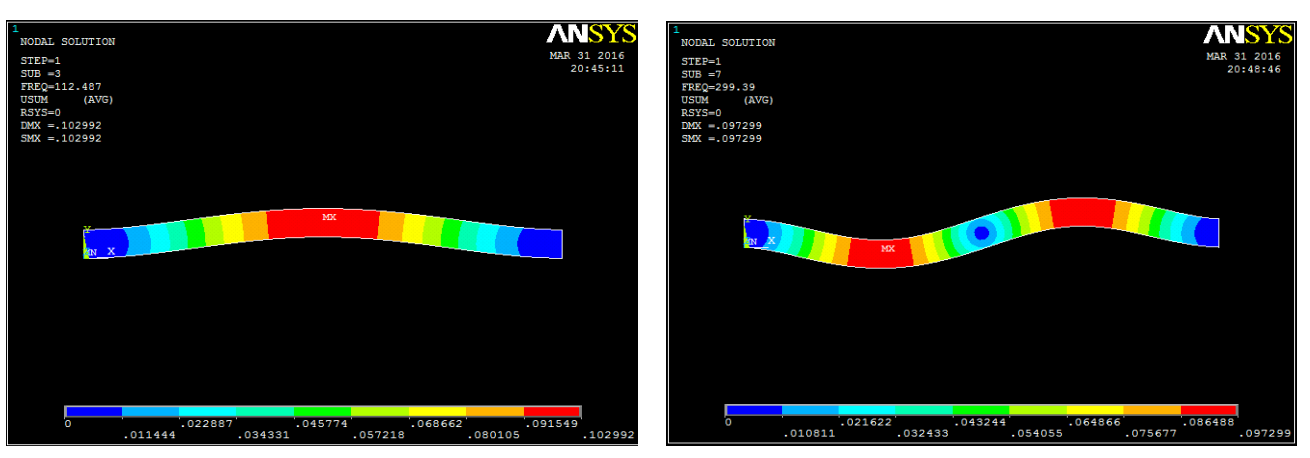
International Journal of Artificial Intelligence and Applications (IJAIA), Vol.9, No.1, January 2018

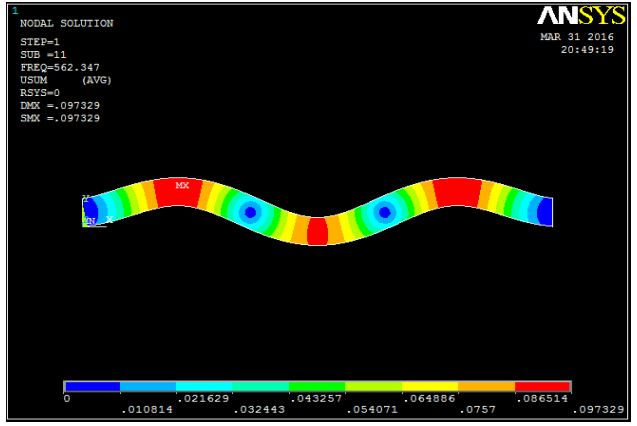

Figure 2. Mode shape deflections obtained from ANSYS for $1^{\text {st }}, 2^{\text {nd }}$ and $3^{\text {rd }}$ modes.

The variation of the first relative natural frequencies verses relative crack location from the fixed end and relative crack depth are as shown in Figure 3 and 4.

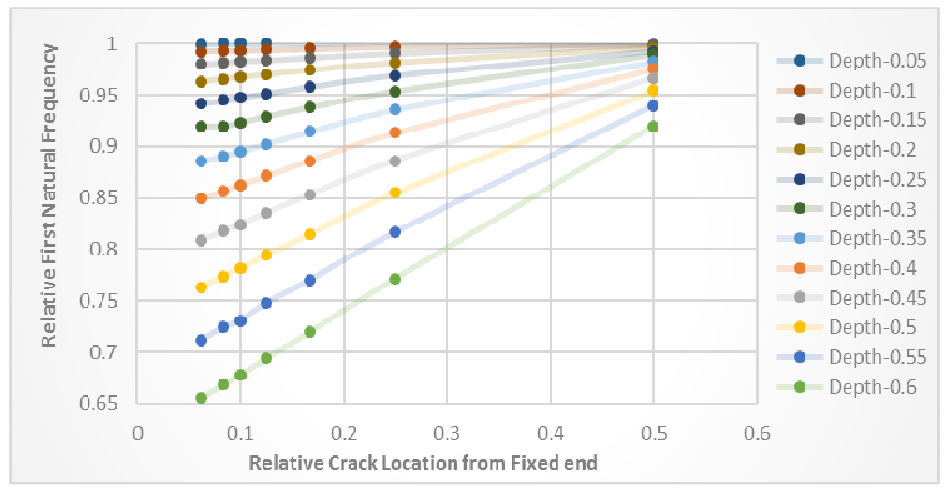

Figure 3. Relative First Natural Frequency variation for same Depth but different Location.

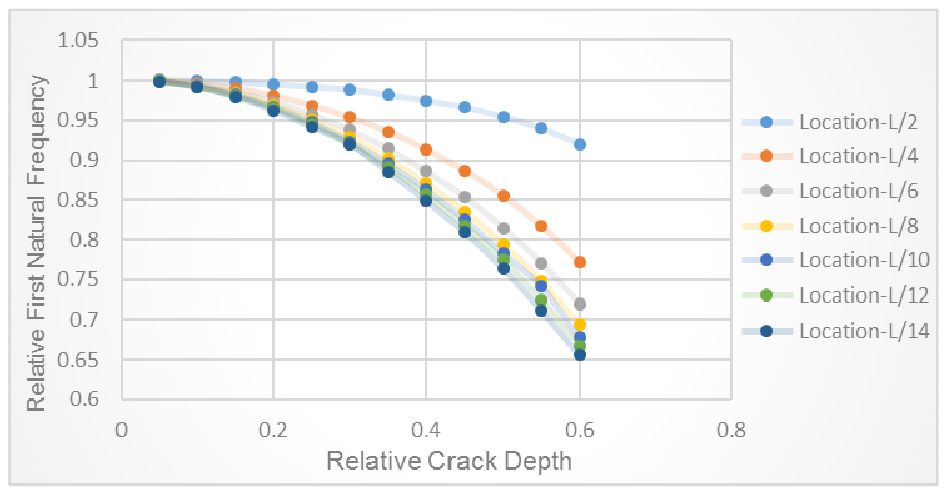

Figure 4. Relative First Natural Frequency variation for same Location but different Depths.

It is evident from Figure 3 that the relative first natural frequency for a flat increase as the distance of the crack is increasing from the fixed end and is maximum at L/2 location (i.e., a relative crack location of 0.5 ). Also it can be observed that the relative first natural frequency decreases as the depth of the crack increases and is minimum for $120 \mathrm{~mm}$ crack depth (i.e., a relative crack depth of 0.6). Further Figure 4 shows that the relative first natural frequency for a flat decrease as the relative depth of the crack increases and is minimum at a crack depth of $120 \mathrm{~mm}$ (i.e., a relative crack depth of 0.6). and also the relative first natural frequency for a flat decrease as the location of the crack is getting nearer to the fixed support and is minimum at L/16 location (i.e., a relative crack location of 0.0625 ). 
International Journal of Artificial Intelligence and Applications (IJAIA), Vol.9, No.1, January 2018

\section{DEVELOPMENT OF FUZZY LOGIC AND ARTIFICIAL NEURAL NeTWORKS AlgorithMS FOR Single CRACK DETECTION}

\subsection{Methodology}

A single crack identification algorithm using both Fuzzy Logic and Artificial Neural Networks has been developed and the performance is evaluated. Both the approaches use vibration response of the structure in its development. These Algorithms for crack detection has been designed with three inputs (first three relative natural frequencies) and two outputs (relative crack locations, relative crack depths). A number of different Fuzzy and ANN algorithms have been used to develop the proposed crack detection methodology. The performance of the best Fuzzy and ANN algorithm used for crack detection out of the developed models has been compared with the results obtained from FEA. To check its suitability for the detection of damage accurately Regression Analysis is performed. Sensitivity Analysis is carried out further to test the robustness of the results including uncertainties obtained from both the approaches. Finally, a comparative study is carried out to identify which approach is best suited for crack detection.

\subsection{Input and Output Parameters for Fuzzy and ANN algorithms}

The Fuzzy and ANN models in this work are developed with three input parameters and two output parameters.

The input parameters used are as follows:

- Relative first natural frequency = "rfnf";

- Relative second natural frequency = "rsnf";

- Relative third natural frequency = "rtnf";

The output parameters used are as follows:

- Relative crack location = "rcl"

- Relative crack depth = "rcd"

\subsection{Fuzzy and ANN Model Properties}

\subsubsection{Details of Fuzzy Logic Models}

The fuzzy models developed in this work are based on Triangular, Trapezoidal and Gaussian membership functions with three input and two output parameters as described in section 4.2.

The pictorial view of the Triangular, Trapezoidal and Gaussian membership fuzzy models is shown in Figure 5(a), (b) and (c) respectively.

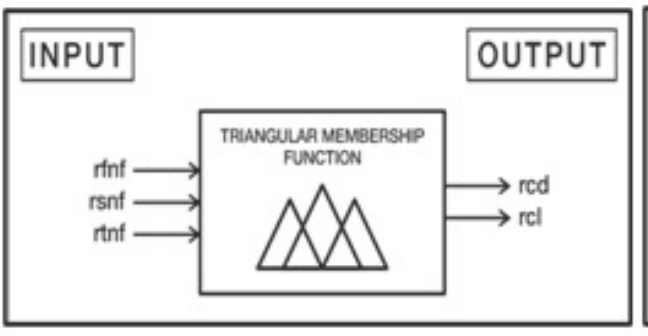

Figure 5(a): Triangular fuzzy model

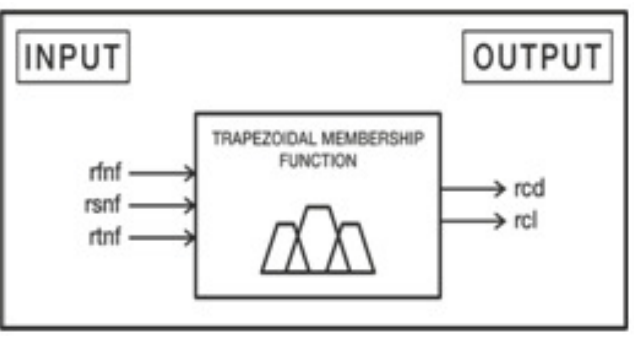

Figure 5(b): Tripezoidal fuzzy model 
International Journal of Artificial Intelligence and Applications (IJAIA), Vol.9, No.1, January 2018

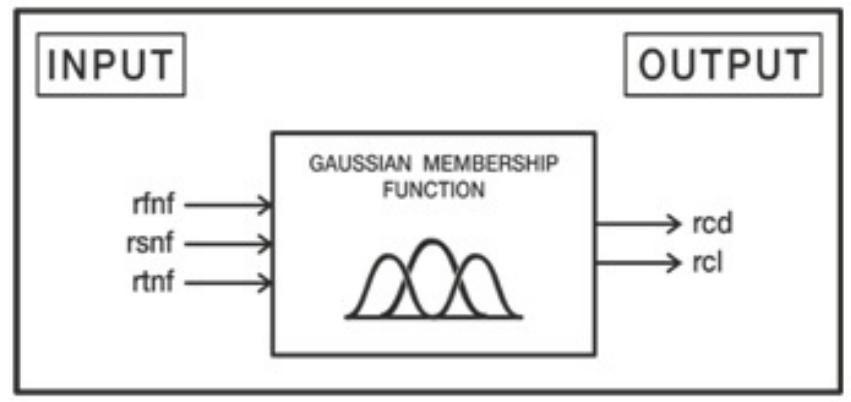

Figure 5(c): Gaussian fuzzy model

The membership functions used in developing the Triangular fuzzy inference system are shown in Figure 6(a), (b), (c), (d) and (e). For all the three fuzzy models, thirty membership functions for each input parameters have been used. Whereas, twelve and ten membership functions have been used for the two output parameters respectively.
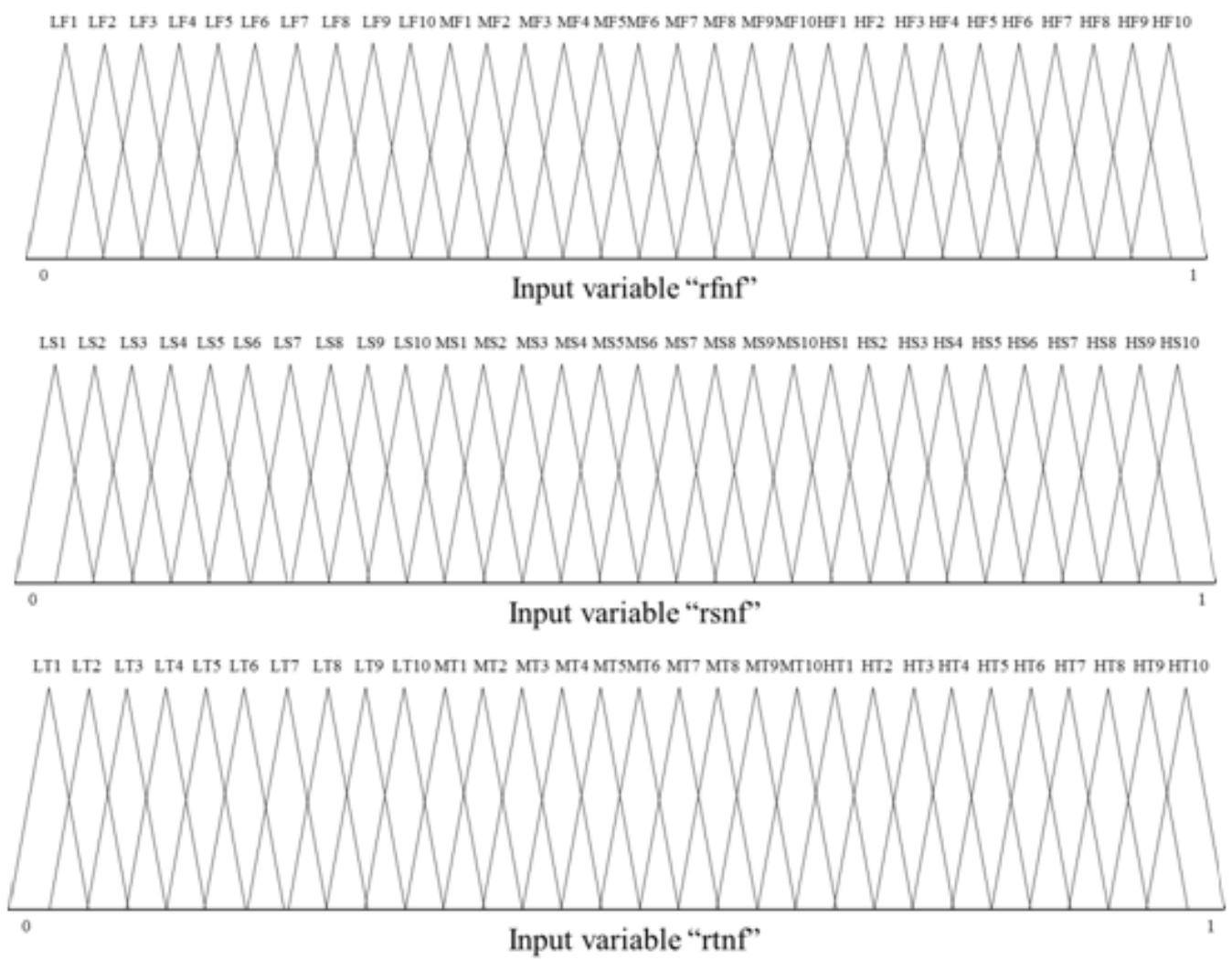

Figure 6(a), (b) and (c): Triangular membership function for relative natural frequency for first, second and third mode of vibrations respectively 
International Journal of Artificial Intelligence and Applications (IJAIA), Vol.9, No.1, January 2018
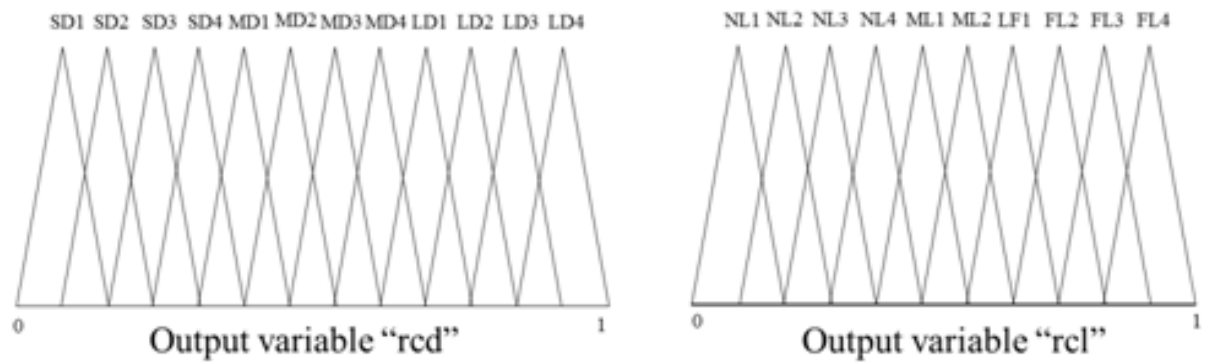

Figure 6(d) and (e): Triangular membership function for relative crack depth and relative crack location respectively

Similar to the above Triangular membership function both Trapezoidal and Gaussian membership functions were also developed.

The fuzzy linguistic terms and examples of some fuzzy rules (Ten) used to design the fuzzy interface systems are represented in Table 4 and Table 5 respectively.

Table 4: Description of fuzzy linguistic terms

\begin{tabular}{|c|c|c|}
\hline $\begin{array}{l}\text { Membership Functions } \\
\text { Name }\end{array}$ & $\begin{array}{l}\text { Linguistic } \\
\text { Terms }\end{array}$ & Description And Range Of Linguistic Terms \\
\hline LF1, LF2 up to LF10 & $\operatorname{rfnf}_{1-10}$ & $\begin{array}{l}\text { Low ranges of relative natural frequency for first mode of } \\
\text { vibration in ascending order respectively. }\end{array}$ \\
\hline MF1, MF2 up to MF10 & $\operatorname{rfnf}_{11-20}$ & $\begin{array}{l}\text { Medium ranges of relative natural frequency for first mode of } \\
\text { vibration in ascending order respectively. }\end{array}$ \\
\hline HF1, HF2 up to HF10 & $\operatorname{rfnf}_{21-30}$ & $\begin{array}{l}\text { High ranges of relative natural frequency for first mode of } \\
\text { vibration in ascending order respectively. }\end{array}$ \\
\hline LS1, LS2 up to LS10 & $\operatorname{rsnf}_{1-10}$ & $\begin{array}{l}\text { Low ranges of relative natural frequency for second mode of } \\
\text { vibration in ascending order respectively. }\end{array}$ \\
\hline MS1, MS2 up to MS10 & $\operatorname{rsnf}_{11-20}$ & $\begin{array}{l}\text { Medium ranges of relative natural frequency for second mode } \\
\text { of vibration in ascending order respectively. }\end{array}$ \\
\hline HS1, HS2 up to HS10 & $\operatorname{rsnf}_{21-30}$ & $\begin{array}{l}\text { High ranges of relative natural frequency for second mode of } \\
\text { vibration in ascending order respectively. }\end{array}$ \\
\hline LT1, LT2 up to LT10 & $\operatorname{rtnf}_{1-10}$ & $\begin{array}{l}\text { Low ranges of relative natural frequency for third mode of } \\
\text { vibration in ascending order respectively. }\end{array}$ \\
\hline MT1, MT2 up to MT10 & $\operatorname{rtnf}_{11-20}$ & $\begin{array}{l}\text { Second ranges of relative natural frequency for third mode of } \\
\text { vibration in ascending order respectively. }\end{array}$ \\
\hline HT1, HT2 up to HT10 & $\operatorname{rtnf}_{21-30}$ & $\begin{array}{l}\text { High ranges of relative natural frequency for third mode of } \\
\text { vibration in ascending order respectively. }\end{array}$ \\
\hline $\mathrm{SD} 1, \mathrm{SD} 2, \mathrm{SD} 3, \mathrm{SD} 4$ & $\operatorname{rcd}_{1-4}$ & $\begin{array}{l}\text { Small ranges of relative crack depth in ascending order } \\
\text { respectively. }\end{array}$ \\
\hline MD1, MD2 & $\operatorname{rcd}_{5,6}$ & $\begin{array}{l}\text { Medium ranges of relative crack depth in ascending order } \\
\text { respectively. }\end{array}$ \\
\hline LD1, LD2, LD3, LD4 & $\operatorname{rcd}_{7-10}$ & $\begin{array}{l}\text { Large ranges of relative crack depth in ascending order } \\
\text { respectively. }\end{array}$ \\
\hline NL1, NL2, NL3, NL4 & $\mathrm{rcl}_{1-4}$ & $\begin{array}{l}\text { Nearer ranges of relative crack depth in ascending order } \\
\text { respectively. }\end{array}$ \\
\hline ML1, ML2, ML3, ML4 & $\mathrm{rcl}_{5,6}$ & $\begin{array}{l}\text { Intermediate ranges of relative crack depth in ascending order } \\
\text { respectively. }\end{array}$ \\
\hline FL1, FL2, FL3, FL4 & $\mathrm{rcl}_{7-10}$ & $\begin{array}{l}\text { Farther ranges of relative crack depth in ascending order } \\
\text { respectively. }\end{array}$ \\
\hline
\end{tabular}


Table 5: Examples of ten fuzzy rules used in the fuzzy models

\begin{tabular}{|l|l|}
\hline Sl. No. & Examples of Some rules used in the fuzzy model \\
\hline 1 & If fnf is HF9, snf is HS10, tnf is HT9 then rcd is SD1 and rcl is FL4 \\
\hline 2 & If fnf is HF8, snf is HS10, tnf is HT8 then rcd is SD2 and rcl is FL4 \\
\hline 3 & If fnf is HF9, snf is HS4, tnf is HT5 then rcd is SD4 and rcl is ML1 \\
\hline 4 & If fnf is HF3, snf is HS10, tnf is MT10 then rcd is MD1 and rcl is FL4 \\
\hline 5 & If fnf is MF10, snf is HS6, tnf is HT9 then red is MD2 and rcl is NL1 \\
\hline 6 & If fnf is LF8, snf is HS4, tnf is HT7 then rcd is LD4 and rcl is NL2 \\
\hline 7 & If fnf is MF9, snf is HS9, tnf is HT3 then red is LD2 and rcl is NL3 \\
\hline 8 & If fnf is HF6, snf is HS5, tnf is MT2 then rcd is LD1 and rcl is NL4 \\
\hline 9 & If fnf is HF5, snf is HS3, tnf is LT4 then rcd is LD3 and rcl is NL4 \\
\hline 10 & If fnf is HF9, snf is HS7, tnf is HT7 then rcd is SD3 and rcl is ML1 \\
\hline
\end{tabular}

\subsubsection{Details of ANN Models}

The ANN models developed in this work are based on feed forward backpropagation network type with three input and two output parameters as described in section 4.2. The back propagation neural network has one input layer and one output layer and different amount of hidden layers. The input layer contains three neurons and the output layer contains two neurons corresponding to the input and output parameters. Whereas the hidden layers contain varying layers of neurons as shown in figure 7. The neurons associated with the input layer of the network represents the first three relative natural frequencies and the neurons associated with the output layer of network represents the relative crack depths and relative crack location.

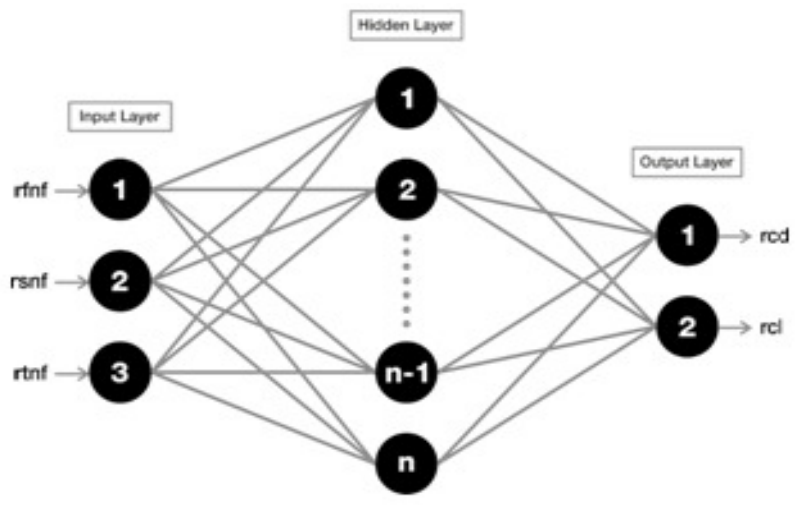

Figure 7. Neural Network Model.

Six different ANN Algorithm were developed using different number of layers and different number of neurons in each layer and the best of them is chosen for further discussion. The network properties and the training parameters of the ANN algorithm are as shown in Table 6.

Table 6. Details of ANN Model.

\begin{tabular}{|l|l|}
\hline \multicolumn{2}{|c|}{ NETWORK PROPERTIES } \\
\hline Network Type & Feed Forward Backpropagation algorithm \\
\hline Training Function & TRAINLM (Levenberg-Marquardt backpropagation) \\
\hline Adaption Learning Function & LEARNGDM \\
\hline Performance Function & MSE (Mean Squared Normalised) \\
\hline Transfer Function & TANSIG \\
\hline Number of Hidden Layers & 1 in first 3 Cases and 2 in the next 3 Cases \\
\hline Number of Neurons in each layer & 8,10 and 12 respectively \\
\hline
\end{tabular}


International Journal of Artificial Intelligence and Applications (IJAIA), Vol.9, No.1, January 2018

\begin{tabular}{|l|l|}
\hline \multicolumn{2}{|c|}{ DATA DIVISION (RANDOM) } \\
\hline Training Data & $70 \%$ (58 Samples) \\
\hline Validation Data & $15 \%$ (13 Samples) \\
\hline Test Data & $15 \%$ (13 Samples) \\
\hline \multicolumn{2}{|c|}{ TRAINING PROPERTIES } \\
\hline Show Window & TRUE \\
\hline Show Command Line & FALSE \\
\hline Show & 25 \\
\hline Epochs & 1000 \\
\hline Time & Inf \\
\hline Min Grad & $1 \mathrm{e}-05$ \\
\hline Max Fail & 1000 \\
\hline Mu & 0.001 \\
\hline Mu_Max & 10000000000 \\
\hline
\end{tabular}

\subsection{Results and Discussions}

\subsubsection{Fuzzy Results}

The results obtained from ANSYS, Fuzzy Triangular, Trapezoidal and Gaussian model after defuzzification are compared in Table 7 (Only few cases).

Table 7. Comparison of results between Fuzzy Triangular, Trapezoidal and Gaussian models.

\begin{tabular}{|c|c|c|c|c|c|c|c|}
\hline \multicolumn{2}{|c|}{ ANSYS } & \multicolumn{6}{c|}{ Fuzzy Models } \\
\hline $\begin{array}{c}\text { Relative } \\
\text { Crack } \\
\text { Depth }\end{array}$ & $\begin{array}{c}\text { Relative } \\
\text { Crack } \\
\text { Location }\end{array}$ & \multicolumn{2}{|l|}{ Triangular Model } & \multicolumn{2}{|c|}{$\begin{array}{c}\text { Trapezoidal } \\
\text { Model }\end{array}$} & \multicolumn{2}{l|}{ Gaussian Model } \\
\hline $\boldsymbol{r c d}$ & $\boldsymbol{r c l}$ & $\boldsymbol{r c d}$ & $\boldsymbol{r c l}$ & $\boldsymbol{r c d}$ & $\boldsymbol{r c l}$ & $\boldsymbol{r c d}$ & $\boldsymbol{r c l}$ \\
\hline 0.05 & 0.5 & 0.0751 & 0.208 & 0.0751 & 0.139 & 0.0762 & 0.22 \\
\hline 0.1 & 0.25 & 0.0883 & 0.25 & 0.092 & 0.25 & 0.0926 & 0.248 \\
\hline 0.15 & 0.1667 & 0.113 & 0.278 & 0.125 & 0.28 & 0.114 & 0.28 \\
\hline 0.2 & 0.125 & 0.126 & 0.119 & 0.13 & 0.13 & 0.13 & 0.161 \\
\hline 0.25 & 0.1 & 0.249 & 0.102 & 0.325 & 0.275 & 0.227 & 0.0985 \\
\hline 0.3 & 0.0833 & 0.299 & 0.0504 & 0.325 & 0.275 & 0.3 & 0.0527 \\
\hline 0.35 & 0.0625 & 0.35 & 0.0501 & 0.35 & 0.0501 & 0.35 & 0.051 \\
\hline 0.4 & 0.5 & 0.4 & 0.5 & 0.4 & 0.5 & 0.4 & 0.499 \\
\hline 0.45 & 0.25 & 0.45 & 0.25 & 0.45 & 0.25 & 0.45 & 0.25 \\
\hline 0.5 & 0.1667 & 0.5 & 0.2 & 0.5 & 0.2 & 0.5 & 0.2 \\
\hline 0.55 & 0.125 & 0.55 & 0.15 & 0.55 & 0.15 & 0.55 & 0.15 \\
\hline 0.6 & 0.1 & 0.598 & 0.102 & 0.375 & 0.275 & 0.598 & 0.0999 \\
\hline 0.6 & 0.0833 & 0.325 & 0.275 & 0.375 & 0.275 & 0.555 & 0.0756 \\
\hline 0.6 & 0.0625 & 0.325 & 0.275 & 0.375 & 0.275 & 0.597 & 0.0528 \\
\hline
\end{tabular}

It can be seen for the Table 7 that the results obtained from the Fuzzy Triangular, Trapezoidal and Gaussian models are in close proximity with the outputs obtained from the FEA results. Thus the developed fuzzy crack detection model/systems can be effectively used in damage detection and a continuous structural health monitoring system can be developed for any system.

To determine the best suited model out of the three models developed, an analysis of $\mathrm{R}^{2}$ value (Regression plots) has been done and results obtained are as tabulated in Table 8. Also the comparison of the values is shown in Figure 8(a) and (b) for relative crack depths and relative crack locations respectively. 
International Journal of Artificial Intelligence and Applications (IJAIA), Vol.9, No.1, January 2018

Table 8. Comparison of $\mathrm{R}^{2}$ values between original output and the outputs obtained from Fuzzy Triangular, Trapezoidal and Gaussian models.

\begin{tabular}{|c|c|c|c|}
\hline \multirow{2}{*}{ SL.No } & \multirow{2}{*}{ Type of Fuzzy Model } & \multicolumn{2}{|c|}{$\mathbf{R}^{2}$} \\
\cline { 3 - 4 } & & rcd & rcl \\
\hline 1 & Triangular Fuzzy Model & $80.30 \%$ & $73 \%$ \\
\hline 2 & Trapezoidal Fuzzy Model & $75.90 \%$ & $53.40 \%$ \\
\hline 3 & Gaussian Fuzzy Model & $98.70 \%$ & $88.40 \%$ \\
\hline
\end{tabular}

Note: A $0.05 \%$ level of significance i.e., a 95\% level of confidence is assumed in determining the $R^{2}$ values

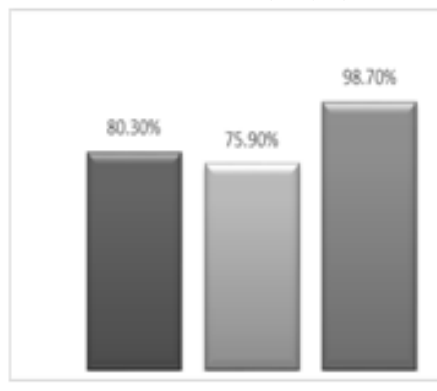

(a) red
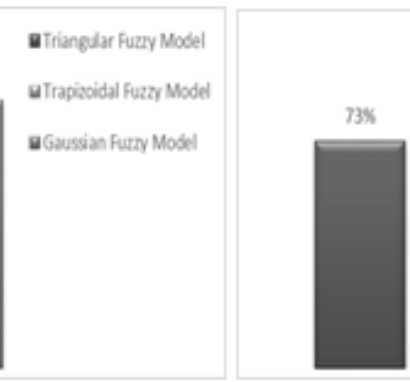

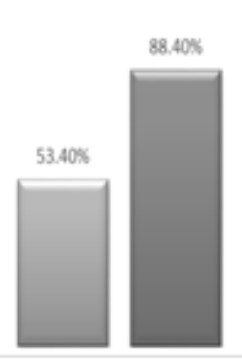

(b) $\mathrm{rcl}$

Figure 8: $\mathrm{R}^{2}$ values between original output and output obtained from fuzzy models for Relative Crack Depth and Relative Crack Location.

It can be seen from Table 8 and Figure 8(a) and (b) that the results obtained from the Fuzzy Gaussian model has the highest $\mathrm{R}^{2}$ value when compared to the Fuzzy Triangular and Trapezoidal models for the determination of both relative crack depths and relative crack locations. Thus Fuzzy Gaussian model can be effectively used in damage detection since it produces the best results for both finding both red and rcl.

\subsubsection{ANN Results}

Six different ANN models were developed and the results obtained are as shown in Table 9. The best ANN Algorithm out of the six networks developed is the one that has the highest percentage of $R^{2}$ value.

Table 9. Structure and Performance of different ANN models developed.

\begin{tabular}{|c|c|c|c|c|c|c|}
\hline Sl.no. & $\begin{array}{c}\text { Number of } \\
\text { Hidden Layers }\end{array}$ & $\begin{array}{c}\text { Numbers of } \\
\text { Neurons }\end{array}$ & $\begin{array}{c}\text { ANN } \\
\text { structure }\end{array}$ & $\begin{array}{c}\text { Iteration } \\
\text { number }\end{array}$ & $\begin{array}{c}\text { Training } \\
\text { Time (sec) }\end{array}$ & $\begin{array}{c}\text { R2 value } \\
\text { in \% }\end{array}$ \\
\hline 1 & 1 & 8 & $3--8--2$ & 24 & 1 & 97.82 \\
\hline $\mathbf{2}$ & $\mathbf{1}$ & $\mathbf{1 0}$ & $\mathbf{3 - - 1 0 - - 2}$ & $\mathbf{7 9}$ & $\mathbf{1}$ & $\mathbf{9 8 . 2 3}$ \\
\hline 3 & 1 & 12 & $3--12--2$ & 83 & 1 & 97.5 \\
\hline 4 & 2 & 8 & $3--8-8--2$ & 164 & 1 & 95.97 \\
\hline 5 & 2 & 10 & $3--10-10--2$ & 92 & 4 & 97.3 \\
\hline 6 & 2 & 12 & $3--12-12--2$ & 781 & 7 & 97.6 \\
\hline
\end{tabular}

The 3-10-2 ANN Structure was found to be the best suitable ANN model for crack detection with a $98.23 \% \mathrm{R}^{2}$ value.

The results obtained from the ANN Model developed are in Table 10 (only few cases). Also the $\mathrm{R}^{2}$ value are as shown in Table 11 . 
International Journal of Artificial Intelligence and Applications (IJAIA), Vol.9, No.1, January 2018

Table 10. Comparison of results obtained from ANN Model and FEA.

\begin{tabular}{|c|c|c|c|c|}
\hline \multirow{2}{*}{ Case No. } & \multicolumn{2}{|c|}{ Original (FEA) } & \multicolumn{2}{c|}{ ANN } \\
\hline & rcd & rcl & rcd & rcl \\
\hline 1 & 0.05 & 0.5 & 0.07519 & 0.24083 \\
\hline 2 & 0.1 & 0.25 & 0.07943 & 0.27894 \\
\hline 3 & 0.15 & 0.16667 & 0.11177 & 0.21126 \\
\hline 4 & 0.2 & 0.125 & 0.17028 & 0.07495 \\
\hline 5 & 0.25 & 0.1 & 0.23316 & 0.08305 \\
\hline 6 & 0.3 & 0.08333 & 0.29177 & 0.08197 \\
\hline 7 & 0.35 & 0.0625 & 0.34208 & 0.06834 \\
\hline 8 & 0.4 & 0.5 & 0.40433 & 0.5 \\
\hline 9 & 0.45 & 0.25 & 0.45149 & 0.25281 \\
\hline 10 & 0.5 & 0.16667 & 0.54498 & 0.17558 \\
\hline
\end{tabular}

It can be seen from the Table 10 that the results obtained from the Artificial Neural network model are in close proximity with the outputs obtained from the FEA results. Thus, the developed ANN crack detection model can be effectively used in damage detection and a continuous structural health monitoring system can be developed for any system.

Table 11. Structure and Performance of different ANN models developed.

\begin{tabular}{|c|c|c|}
\hline \multirow{2}{*}{ Type } & \multicolumn{2}{|c|}{ R2 } \\
\cline { 2 - 3 } & rcd & rcl \\
\hline ANN Model & $98.30 \%$ & $92 \%$ \\
\hline
\end{tabular}

Note: A $0.05 \%$ level of significance i.e., a 95\% level of confidence is assumed in determining the $R^{2}$ values.

It can also be seen from the Table 11 that the results obtained from the ANN model has very good $\mathrm{R}^{2}$ value for the determination of both relative crack depths and relative crack locations. Thus ANN model can be effectively used in damage detection since it produces the best results for finding both red and rcl.

\subsection{Sensitivity Analysis on the Fuzzy and ANN Models Developed}

In order to know the robustness of the Fuzzy and ANN models developed a sensitivity analysis has been made. This is carried out by changing the values of relative first natural frequency, relative second natural frequency and relative third natural frequency by $0.1 \%$ one after the other respectively. The details of the results obtained in terms of the $R^{2}$ values are tabulated in Table 12 and 13. Also the comparison of these values are shown in Figure 9(a) and (b), 10(a) and (b), 11(a) and (b), 12(a) and (b) for rcd and rcl respectively.

Table $12 . \mathrm{R}^{2}$ value after sensitivity analysis for the ANN model developed.

\begin{tabular}{|c|c|c|c|}
\hline \multirow{2}{*}{$\begin{array}{c}\text { SL } \\
\text { No }\end{array}$} & \multirow{2}{*}{ Type } & \multicolumn{2}{|c|}{$\mathbf{R}^{\mathbf{2}}$} \\
\cline { 3 - 4 } & & rcd & rcl \\
\hline 1 & ANN Model & $98.30 \%$ & $92 \%$ \\
\hline 2 & $0.1 \%$ increase in $r f n f$ & $98.20 \%$ & $85.70 \%$ \\
\hline 3 & $0.1 \%$ increase in $r s n f$ & $98.20 \%$ & $90.70 \%$ \\
\hline 4 & $0.1 \%$ increase in $r t n f$ & $98.20 \%$ & $89.20 \%$ \\
\hline
\end{tabular}


International Journal of Artificial Intelligence and Applications (IJAIA), Vol.9, No.1, January 2018

Table $13 . \mathrm{R}^{2}$ value after sensitivity analysis for the ANN model developed.

\begin{tabular}{|c|c|c|c|c|c|c|c|}
\hline \multirow{2}{*}{$\begin{array}{l}\text { SL. } \\
\text { No. }\end{array}$} & $\begin{array}{c}\text { Type of } \\
\text { Fuzzy Model }\end{array}$ & \multicolumn{2}{|c|}{$\begin{array}{c}\mathbf{R}^{2} \text { value - for } 0.1 \% \\
\text { increase in RFNF }\end{array}$} & \multicolumn{2}{c|}{$\begin{array}{c}\mathbf{R}^{2} \text { value - for } 0.1 \% \\
\text { increase in RSNF }\end{array}$} & \multicolumn{2}{c|}{$\begin{array}{c}\mathbf{R}^{2} \text { value -for } 0.1 \% \\
\text { increase in RTNF }\end{array}$} \\
\cline { 3 - 8 } & & red & rcl & rcd & rcl & rcd & rcl \\
\hline 1 & Triangular & $54.80 \%$ & $53 \%$ & $80.30 \%$ & $73 \%$ & $80.30 \%$ & $73 \%$ \\
\hline 2 & Trapezoidal & $46.90 \%$ & $39.80 \%$ & $75.90 \%$ & $53.40 \%$ & $75.90 \%$ & $53.40 \%$ \\
\hline 3 & Gaussian & $98.00 \%$ & $84.40 \%$ & $98.70 \%$ & $88.40 \%$ & $98.70 \%$ & $88.40 \%$ \\
\hline
\end{tabular}

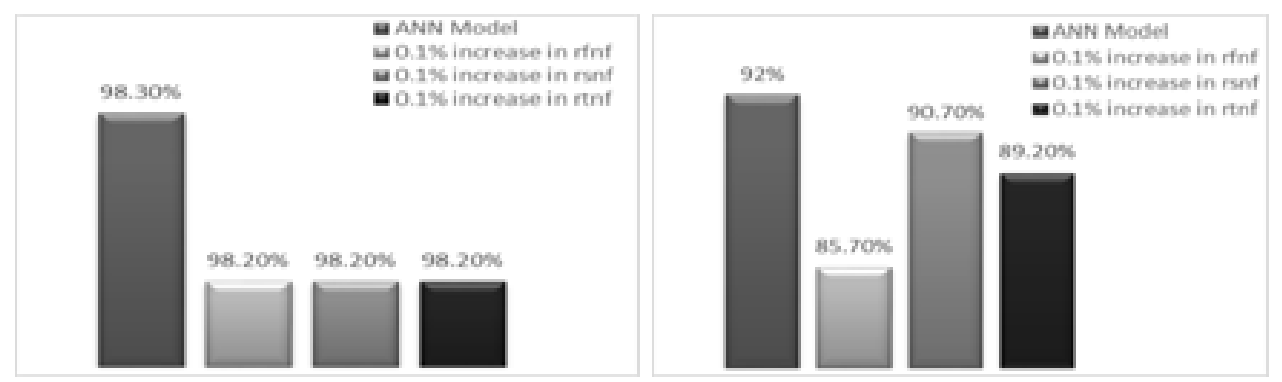

(a) rcd

(b) $\mathrm{rcl}$

Figure 9: Comparison of $\mathrm{R}^{2}$ Values for Relative crack depth (a) and Relative crack location (b) by increasing rfnf, rsnf and $\mathrm{rtnf}$ by $0.1 \%$.

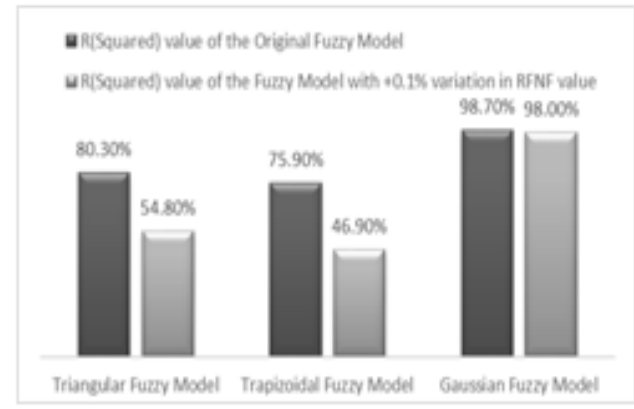

(a) $\mathrm{rcd}$

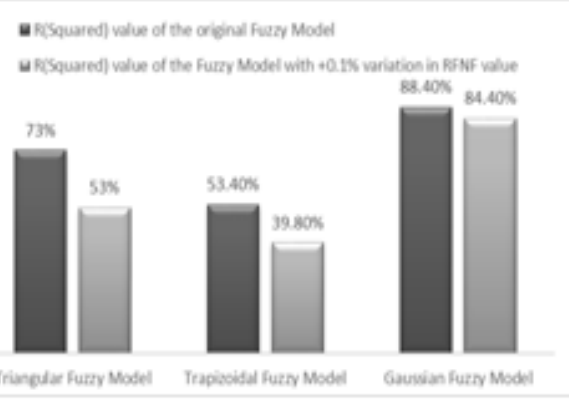

(b) $\mathrm{rcl}$

Figure 10: Comparison of $\mathrm{R}^{2}$ Values for Relative crack depth (a) and Relative crack location (b) by increasing $\mathrm{rfnf}$, rsnf and $\mathrm{rtnf}$ by $0.1 \%$.

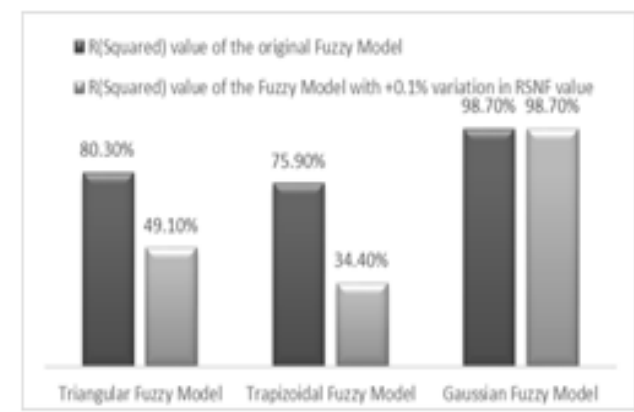

(a) $\mathrm{rcd}$

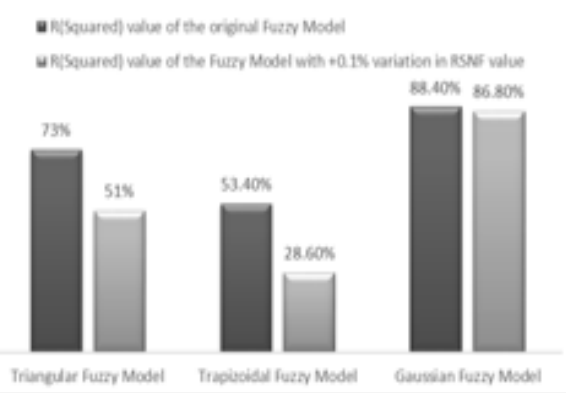

(b) $\mathrm{rcl}$

Figure 11: Comparison of $\mathrm{R}^{2}$ Values for Relative crack depth (a) and Relative crack location (b) by increasing $\mathrm{rfnf}$, rsnf and $\mathrm{rtnf}$ by $0.1 \%$. 


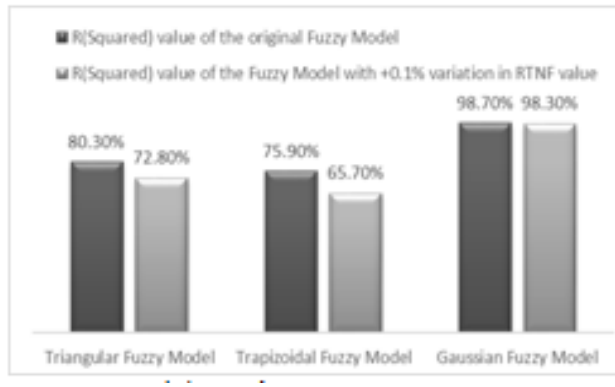

(a) $\mathrm{rcd}$

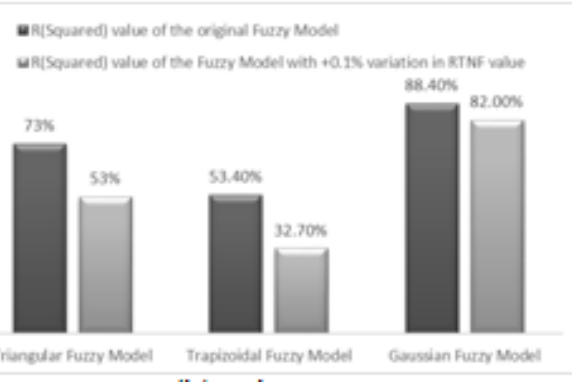

(b) $\mathrm{rcl}$

Figure 12: Comparison of $\mathrm{R}^{2}$ Values for Relative crack depth (a) and Relative crack location (b) by increasing rfnf, rsnf and $\mathrm{rtnf}$ by $0.1 \%$.

It can be seen for the Table 12 and 13 that when a sensitivity analysis was done by changing the input values in order to check whether the proposed model can incorporate uncertainties in it, the results obtained from the ANN and Fuzzy Gaussian models with and without change in the input values has the $\mathrm{R}^{2}$ value close to each other when compared to the Original ANN, Fuzzy Triangular and Trapezoidal models for the determination of both relative crack depths and relative crack locations respectively. Thus ANN and Fuzzy Gaussian models can be effectively used in damage detection even with some uncertainties in the input data since it produces the best results for finding both red and rcl.

\section{COMPARISON OF FUZZY AND ANN ALGORITHMS}

A comparison was made between the best Fuzzy Model and best Artificial Neural Networks Model developed and the results obtained are as tabulated below in Table 14 and Figure 13(a) and (b). The results tabulated in Table 15 and shown in Figure 14(a) and (b) were obtained after sensitivity analysis.

Table 14: $\mathrm{R}^{2}$ values for ANN Model and Gaussian Fuzzy Model developed

\begin{tabular}{|c|c|c|c|}
\hline \multirow{2}{*}{ SL.No } & \multirow{2}{*}{ Type } & \multicolumn{2}{|c|}{$\mathbf{R}^{2}$} \\
\cline { 3 - 4 } & & rcd & rcl \\
\hline 1 & ANN Model & $98.30 \%$ & $92 \%$ \\
\hline 2 & Gaussian Fuzzy Model & $98.70 \%$ & $88.40 \%$ \\
\hline
\end{tabular}

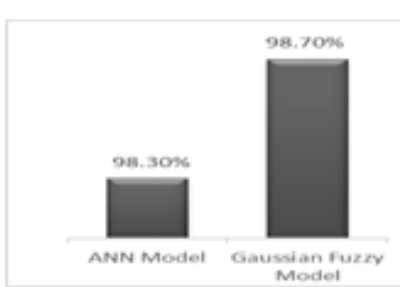

(a) rcd

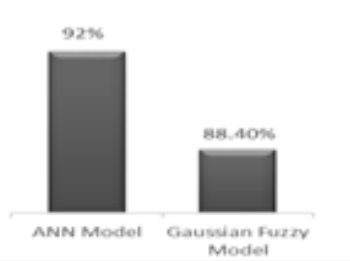

(b) $\mathrm{rcl}$

Figure 13: $\mathrm{R}^{2}$ values for ANN Model and Gaussian Fuzzy Model developed for Relative crack depth and relative crack location Respectively

It can be seen from the Table 14 that both ANN model and Gaussian Fuzzy model gave a close $\mathrm{R}^{2}$ value to each other. Out of which Gaussian Fuzzy Model performed better in determining Relative crack depth and ANN model performed better in determining Relative crack location. 
International Journal of Artificial Intelligence and Applications (IJAIA), Vol.9, No.1, January 2018

Table 15: $\mathrm{R}^{2}$ values for ANN Model and Gaussian Fuzzy Model developed before and after performing sensitivity analysis

\begin{tabular}{|c|c|c|c|}
\hline \multirow{2}{*}{ SL.No } & \multirow{2}{*}{ Type } & \multicolumn{2}{|c|}{$\mathbf{R}^{\mathbf{2}}$} \\
\cline { 3 - 4 } & & rcd & rcl \\
\hline 1 & ANN Model & $98.30 \%$ & $92 \%$ \\
\hline & Gaussian Fuzzy Model & $98.70 \%$ & $88.40 \%$ \\
\hline 2 & $0.1 \%$ increase in rfnf (ANN) & $98.20 \%$ & $85.70 \%$ \\
\hline & $0.1 \%$ increase in rfnf (FGM) & $98.30 \%$ & $84.40 \%$ \\
\hline 3 & $0.1 \%$ increase in rsnf (ANN) & $98.20 \%$ & $90.70 \%$ \\
\hline & $0.1 \%$ increase in rfnf (FGM) & $98.70 \%$ & $86.80 \%$ \\
\hline 4 & $0.1 \%$ increase in rtnf (ANN) & $98.20 \%$ & $89.20 \%$ \\
\hline & $0.1 \%$ increase in rfnf (FGM) & $98.30 \%$ & $82 \%$ \\
\hline
\end{tabular}

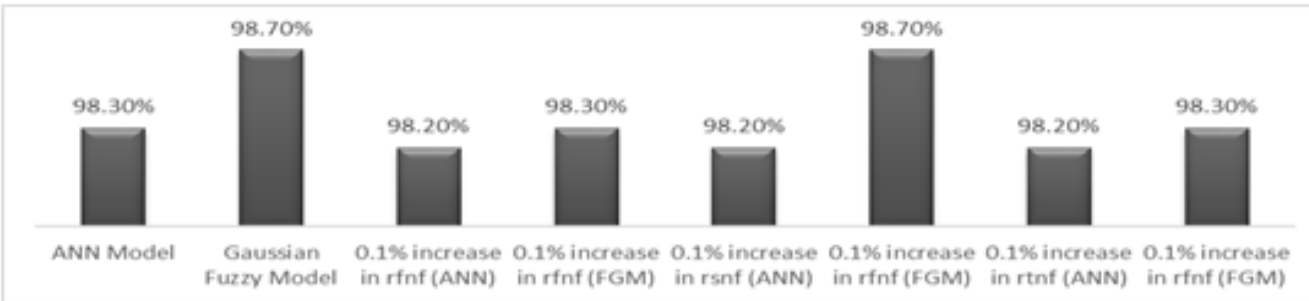

Figure 14(a): $\mathrm{R}^{2}$ values for ANN Model and Gaussian Fuzzy Model developed for Relative crack depth before and after performing sensitivity analysis

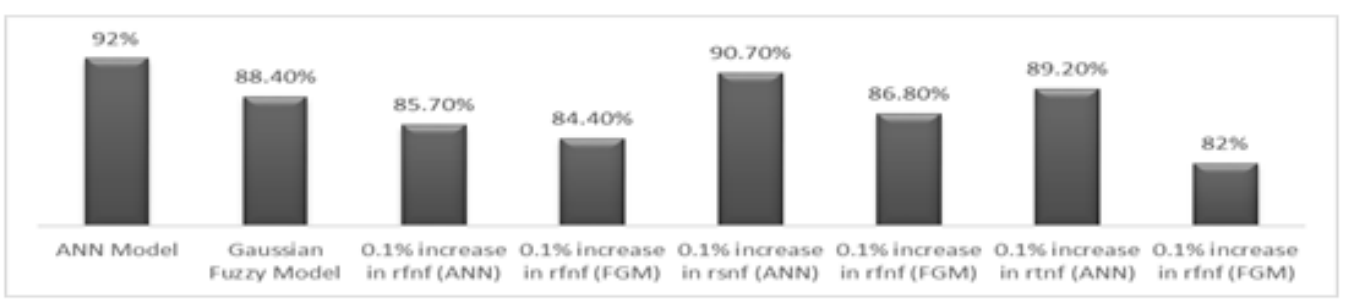

Figure 14(b): $\mathrm{R}^{2}$ values for ANN Model and Gaussian Fuzzy Model developed for Relative crack location before and after performing sensitivity analysis.

It can be seen for the Table 15 that both ANN model and Gaussian Fuzzy model gave slightly different $\mathrm{R}^{2}$ value on the results obtained after the sensitivity analysis. Out of which Gaussian Fuzzy Model performed better in determining Relative crack depth and ANN model performed better in determining Relative crack location.

\section{Conclusions}

Whenever there is a damage introduced in a structure there is a change in the dynamic properties of the structure such as Natural Frequency and Mode Shapes these changes are less predominant unless the damage is very severe. Natural frequency of a structure decreases as the depth of the crack increases since there is a reduction in the stiffness of the structure due the development of crack. Based on the above details this paper presents two crack detections algorithms one using Fuzzy Logic and other using Artificial Neural Networks on a fixed beam like structure (flat). Further a comparison has been made to identify which algorithm is best suited for a single crack detection. Both ANN and Fuzzy logic can be used in developing an effective damage detection algorithm based on the results obtained. Out of the three types of fuzzy models developed, the Fuzzy Gaussian model gave the best results when compared to the Fuzzy Triangular and Trapezoidal Models. Even while handling the input data with some uncertainties, both ANN and 
International Journal of Artificial Intelligence and Applications (IJAIA), Vol.9, No.1, January 2018

Fuzzy Gaussian model gave almost accurate results when compared to the other two models. Between the Fuzzy Gaussian Model and ANN Model developed the Fuzzy Gaussian Model was more accurate in determining the relative crack depth whereas the ANN Model was more accurate in determining the relative crack location. Therefore, a research can be further carried out in developing a hybrid model combining the ANN and Fuzzy Logic which can be an effective method to detect damage in structures. Care should be taken to select the best type of membership function to be used in case of fuzzy logic. Whereas, in case of ANN determination of optimum number of hidden layers and the number of neurons that should be present in each layer is crucial.

\section{REFERENCES}

[1] L. A. Zadeh, (1965) “L. A. Zadeh: Fuzzy Sets”, Information and Control, Vol. 8, pp338-358.

[2] Kamalanathan S and Selvaraju S, (2012), "Collaborative Approaches for Personalized Web Search Using Fuzzy Neural Networks”. In: Krishna P.V., Babu M.R., Ariwa E. (eds) Global Trends in Information Systems and Software Applications. Communications in Computer and Information Science, Vol. 270, pp367-376.

[3] G.Vellidis, M.T. C.Perry, C.Kvien and C.Bednarz, (2008), "A real-time wireless smart sensor array for scheduling irrigation", Computers and electronics in agriculture, Vol. 61, pp44-50.

[4] M. H. Richardson, (1980) "Detection of damage in structures from changes in their dynamic (Modal) properties-a survey,” Tech. Rep. NUREG/CR-1431, UCLR-15103, Structural Measurement Systems, Washington, DC, USA, 1980.

[5] A. Rytter, (1993), "Vibration based inspection of civil engineering structures" [Ph.D. thesis], Aalborg University, Copenhagen, Denmark.

[6] A. D. Dimarogonas, (1996) "Vibration of cracked structures: a state of the art review," Engineering Fracture Mechanics, vol. 55, no.5, pp831-857.

[7] R. Ganguli, (2001) "A fuzzy logic system for ground based structural health monitoring of a helicopter rotor using modal data", Journal of Intelligent Material Systems and Structures, vol. 12, no.6, pp397-407.

[8] L. J. DeMiguel and L. F. Bl'azquez, (2005) "Fuzzy logic-based decision making for fault diagnosis in a DC motor", Engineering Applications of Artificial Intelligence, vol. 18, no. 4, pp423-450.

[9] Bakhary, N., Hao, H. \& Deeks A.J, (2007), "Damage detection using artificial neural network with consideration of uncertainties”, Engineering Structures, Vol. 29, pp2806-2815.

[10] M. Chandrashekhar and R. Ganguli, (2009) "Damage assessment of structures with uncertainty by using mode-shape curvatures and fuzzy logic", Journal of Sound and Vibration, vol. 326, no. 3-5, pp939-957.

[11] Parhi, D.R. \& Das, H.C, (2009), "Application of Neural network for fault diagnosis of cracked cantilever beam", World Congress on Nature and Biologically Inspired Computing, NABIC, pp13031308 .

\section{AUTHORS}

B. Prakruthi Gowd, Assistant Professor, Civil Engineering Department and Presently pursuing Ph.D in the field of Structural Health Monitoring. Gold medalist in M.Tech, Structural Engineering. The research area is Damage Detection in Structures using Vibration based Damage Detection Techniques (Wavelet Transforms, Fuzzy Logic and Artificial Neural Network).

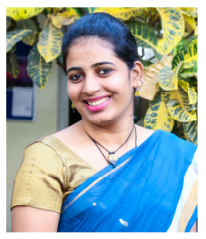


International Journal of Artificial Intelligence and Applications (IJAIA), Vol.9, No.1, January 2018

Dr. K. Jayasree, Assistant Professor, Civil Engineering Department has obtained PhD in Transportation Engineering from JNT University and has 12 years of teaching and/ research experience. She has also worked as a scientist in NATPAC, Kerala. She has developed an operational tool for urban planners to address mobility problems in urban areas. Her research area includes application of fuzzy logic and multi criteria evaluation techniques to civil engineering problems, application of GIS in transportation planning and infrastructure design.

Dr. Manjunatha N. Hegde, Dean-Academic, Professor of Civil Engineering, has obtained $\mathrm{PhD}$ degree in Civil Engineering from Indian Institute of Science (IISc) and has 31 years of teaching and/ research experience. His research area includes FEM in Stochastic Structural Dynamics \& Earthquake Engineering, Fibre Reinforced Concrete, System Identification, Damage Assessment and health Monitoring of Civil Infrastructures, and Life Cycle Energy Cost of Buildings. He is the member of Professional bodies like IEI, ISTE, ISET, ICI, ACCE (I), and INSTRUCT. He is the Member of Board of Studies and/ Examinations of Autonomous Engineering Colleges under VTU.
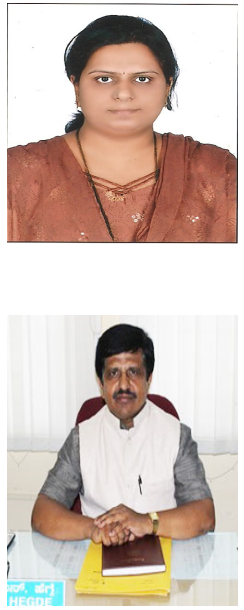